\title{
Larvicidal and Repellent Properties of Streptomyces sp. VITJS4 Crude Extract against Anopheles stephensi, Aedes aegypti and Culex quinquefasciatus (Diptera: Culicidae)
}

\author{
S. JEMIMAH NAINE and C. SUBATHRA DEVI* \\ Industrial Biotechnology Division, School of Biosciences and Technology, \\ VIT University, Vellore, Tamil Nadu, India
}

Submitted 13 March 2014, revised 16 June 2014, accepted 13 August 2014

\begin{abstract}
The aim of the present study was to assess the larvicidal and repellent properties of marine Streptomyces sp. VITJS4 crude extracts. The marine soil samples were collected from the Puducherry coast, Tamil Nadu, India. The isolate Streptomyces sp. VITJS4 was taxonomically characterized and identified. The ethyl acetate crude extract tested for larvicidal property showed 100\% mortality for all the 3 species after $24 \mathrm{~h}$ exposure against the early fourth instar larvae of malarial vector - Anopheles stephensi at 50\% and 90\% lethal concentration $\left(\mathrm{LC}_{50}=132.86, \mathrm{LC}_{90} 396.14 \mathrm{ppm}\right)$; dengue vector - Aedes aegypti $\left(\mathrm{LC}_{50}=112.78, \mathrm{LC}_{90} 336.42 \mathrm{ppm}\right)$ and filariasis vector - Culex quinquefasciatus $\left(\mathrm{LC}_{50}=156.53, \mathrm{LC}_{90} 468.37 \mathrm{ppm}\right)$. The Streptomyces sp. VITJS4 solvent extracts of hexane, ethyl acetate, benzene, chloroform and methanol were tested for repellent activity against A. stephensi, A. aegypti and C. quinquefasciatus. The ethyl acetate extract showed complete protection for $210 \mathrm{~min}$ at $6 \mathrm{mg} / \mathrm{cm}^{2}$ against these mosquito bites. The crude extract was analyzed further for Fourier Transform-infrared spectroscopy (FT-IR) analysis. In addition to the importance of bioactive compounds, the utilization of Streptomyces sp. VITJS4 crude extracts revealed effective larvicidal and repellent activity against the vectors, which perhaps represents a promising tool in the management of mosquito control.
\end{abstract}

Ke y words: Streptomyces sp. VITJS4, insecticides, biological control, eco-friendly

\section{Introduction}

Mosquitoes are the most important arthropod disease vectors, transmitting dreadful human diseases in over 100 countries, causing the mortality of nearly two million people every year (Kundsen and Slooff, 1992; Klempner et al., 2007). They spread many dreadful diseases such as filariasis, malaria, dengue, yellow fever and Japanese encephalitis, which contribute significantly to disease burden, death, poverty and social debility in tropical countries (Jang et al., 2002). Dengue is transmitted to humans through the bite of the mosquito Aedes aegypti (Diptera: Culicidae) which causes a severe flu-like illness. Since there is no specific treatment or vaccine for dengue, the only method of controlling or preventing dengue virus transmission is to combat the vector mosquito by using environmental management and chemical methods (Santos et al., 2001). It is estimated that there are between 50 and 100 million cases of dengue fever and about 500,000 cases of dengue hemorrhagic fever each year which require hospitalization (Maheswaran et al., 2008). Anopheles stephensi transmits malaria in the plains of rural and urban areas of India. Malaria afflicts $36 \%$ of the world population, i.e., 2 milliard in 107 countries and territories situated in the tropical and subtropical regions. In the South East Asian region of the World Health Organization (WHO), out of about 1.4 billion people, 1.2 billion (85.7\%) are exposed to the risk of malaria and most of them live in India. Of the 2.5 million reported cases in the Southeast Asia, India alone contributes about 70\% of the total cases (Kondrachine, 1992). Another vector of Culex quinquefasciatus has been recorded the year round in different parts of the country (Chand et al., 1988). C. quinquefasciatus, the mosquito species commonly found in rural areas is known to cause severe biting nuisance. It is an important vector of lymphatic filariasis caused by nematodes such as Wuchereria bancrofti and Brugiamalayi in humans in some parts of India. Globally over 100 million individuals are affected due to filariasis annually (Ahmed et al., 1984). As mosquitoes are water breeders their larval stages are attractive targets of pesticides (Rawani et al., 2010). It is known that larvicides play a vital role in controlling

* Corresponding author: C. Subathra Devi, School of Biosciences and Technology, VIT University, Vellore, Tamil Nadu, India; fax. 91-416-2243092; e-mail: csubathradevi@vit.ac.in, subaresearch@rediffmail.com 
mosquitoes in their breeding sites (Amer and Mehlhorn, 2006). Synthetic chemical larvicides continue to be applied for controlling mosquitoes in most parts of the world, especially with organophosphate and pyrethroid larvicides (Rahuman et al., 2009). But many of these chemicals are toxic to human, plant, animal life.

Although various biocontrol measures are in vogue, their effective control of larval mosquitoes has not been hitherto highlighted. Microorganisms and microbial products with potential insecticidal activity can play an important role in controlling diseases by interrupting the transmission mechanism by killing insect vectors at the community level (Patil et al., 2011). Mosquito control therefore, continues to be an important strategy in preventing mosquito-borne diseases. Microbial control of insect vector populations can be highly effective and generally has advantages over chemical control because many are host specific and safe for non-target organisms (Carlos et al., 2011). The common mosquito larvicides nowadays include an organophosphate temephos, methoprene. However, the high amount of chemical larvicides could lead to long-term residual effects to the environment and chronic effects on non-target organisms. Almost $80 \%$ of the world's antibiotics are known to come from actinomycetes, mostly from the genera Streptomyces and Micromonospora. Due to this property, marine actinobacteria have received attention. It has been proposed that these antimicrobials are used in competition between microorganisms, offering an advantage to the producer strains (Jensen et al., 2005). Actinobacteria are Gram-positive, filamentous organisms dwelling in the soil (Sanglier et al., 1993). They are widespread in distribution (Deepika et al., 2009) and produce a vast array of secondary metabolites, including enzymes (Strohl, 2004; Berdy, 2005), antibiotics (Blunt, 2006), anti-helminthics (Bibb, 2005), immunomodulators (Mann, 2001). A new larvicidal antibiotic, aculeximycin was found in the culture broth of an actinomycete identified as Streptosporangium albidum which exhibits strong larvicidal activity against mosquito larvae (Ikemoto et al., 1983). Hence the present study was aimed to investigate the larvicidal and repellent properties of marine Streptomyces sp. VITJS4 crude extract.

\section{Experimental}

\section{Materials and Methods}

Marine soil collection and isolation. Marine soil samples were collected from the South East coast of India, Puducherry - Thavalakuppam $\left(11.52^{\circ} \mathrm{N}, 79.47^{\circ} \mathrm{E}\right)$, at the depth of $10-100 \mathrm{~cm}$ at littoral zone and the collected samples were stored at $4^{\circ} \mathrm{C}$. The well defined adaptation of marine Streptomyces species requires sea- water for growth (Macleod, 1965). The isolation was performed on selective media such as actinomycetes isolation agar, Kuster's agars, Bennett agar, Starch casein agar supplemented with $25 \%$ marine water and $25 \%$ marine soil extract for effective isolation. All the plates were incubated at $30^{\circ} \mathrm{C}$ for $1-2$ weeks. Emerging colonies were sub cultured on ISP2 agar and stored at $4^{\circ} \mathrm{C}$.

Taxonomic investigation. The micro-morphological studies and species level characterization was based on morphological, cultural and physiological characteristics following the directions given for the International Streptomyces project (ISP) and Bergey's Manual of Determinative Bacteriology (Shirling and Gottlieb., 1966; Lechevalier and Lechevalier, 1970; Buchanan and Gibbons, 1974). Colours were determined according to the scale adopted (Prauser, 1964). The colour of sporulating aerial mycelia and the growth of actinomycetes was determined on starch casein agar plates and compared with key guidelines (Nonomura, 1974)

Fermentation and extraction. The potent isolate Streptomyces sp. VITJS4 was inoculated on starch casein broth at a seed concentration of $100 \mathrm{ml}$ in a $250 \mathrm{ml}$ Erlenmeyer flask at an incubation period of 7 days at room temperature and the medium was adjusted to $\mathrm{pH}$ 7.2. Various solvents including hexane, chloroform, benzene, methanol and ethyl acetate was used for the extraction process (Remya and Vijayakumar, 2007). All the crude extract powder was weighed and stored for further use.

Insect rearing. A. aegypti, A. stephensi and C.quinquefasciatus larvae were collected from rice field and stagnant water areas of Vellore and identified in Zonal Entomological Research Centre, Chennai, Tamil Nadu, India. The larvae were kept in plastic and enamel trays containing tap water. They were maintained and reared in the laboratory as per the method described (Kamaraj et al., 2009). All the experiments were carried out at $27^{\circ} \mathrm{C}$. Larvae were fed a diet of brewer's yeast, dog biscuits and algae collected from ponds in a ratio of $3: 1: 1$, respectively. Pupae were transferred from the trays to a cup containing tap water and were maintained $(45 \times 45 \times 40 \mathrm{~cm})$ till adults emerged and were maintained in glass cages provided with $10 \%$ sucrose solution in a jar with a cotton wick. On day 5 , the adults were given a blood meal from a pigeon placed in resting cages overnight for blood feeding by females.

Larvicidal bioassay. During preliminary screening with the laboratory trial, the larvae of A. aegypti, A.stephensi and C.quinquefasciatus were collected from the insect-rearing cage. The larvicidal activity was assessed by the procedure of WHO with some modification (Rahuman et al., 2009). For bioassay test, larvae were taken in five batches of 20 in $249 \mathrm{ml}$ of water and $1 \mathrm{ml}$ of the desired Streptomyces sp. VITJS4 ethyl acetate extract. The numbers of dead larvae were counted 
after $24 \mathrm{~h}$ of exposure and the percentage of mortality was reported from the average of five replicates. The experimental set up at which $100 \%$ mortality of larvae occurred were selected for dose response bioassay.

Repellent bioassay. The stock solutions of the extracts were diluted with polysorbate 80 and distilled water to obtain test solutions of $1.0,3.0$ and $6.0 \mathrm{mg} / \mathrm{cm}^{2}$ hexane, ethyl acetate, benzene, chloroform and methanol prepared separately. For repellent experiment, 50 laboratory reared blood-starved adult female mosquitoes between 3 and 10 days old were placed into laboratory cages $(45 \times 45 \times 40 \mathrm{~cm})$. Before each test, the forearm and hand of a human subject were washed with unscented neutral soap, thoroughly rinsed and allowed to dry for $10 \mathrm{~min}$ before extract application. The different Streptomyces sp. VITJS4 extracts were applied from the elbow to the fingertips. The arm was left undisturbed. An arm treated with acetone and polysorbate 80 served as a control. The control and treated arms were introduced simultaneously into the cage. The number of bites was counted over 15 min, every $30 \mathrm{~min}$ and from 180 to $210 \mathrm{~min}$. Protection time was recorded as the time elapsed between repellent application and the observation period immediately once a confirmed bite was obtained. If no bites were confirmed at $210 \mathrm{~min}$, tests were discontinued and protection time was recorded as $210 \mathrm{~min}$. The number of mosquitoes attempting to bite the control arm during the observation period was recorded. The experiments were conducted five times in separate cages. The percentage protection was calculated by using the following formula (Fradin and Day, 2002).
Protection $=(\{$ No. of bites received by control arm $\}$ - $\{$ No. of bites received by treated $\operatorname{arm}\}$ ) / No. of bites received by control arm X 100

Infrared spectroscopy. FT-IR has proven to be a valuable tool for the characterization and identification of compounds or chemical bonds present in an unknown mixture (Eberhardt et al., 2007; Hazra et al., 2007). The FT-IR spectra of the ethyl acetate crude extract samples were recorded on a Thermo Nicolet, Avatar 370 spectrometer equipped with a Deuterated triglycine sulphate detector (DTGS) over the $4000-400 \mathrm{~cm}^{-1}$ range at the resolution of $4 \mathrm{~cm}^{-1}$ and a maximum source aperture and the infrared spectra of the crude extracts were measured (as $\mathrm{KBr}$ discs).

Data analysis. The average parasite mortality data were subjected to probit analysis for calculating $\mathrm{LC}_{50}$ and other statistics at 95\% fiducial limits of upper confidence limit (UCL) and lower confidence limit (LCL) were calculated.

\section{Results}

The present investigation was carried out with an aim to develop a safe and eco-friendly strategy and to explore the larvicidal and repellent activity of marine Streptomyces as a sustainable source for the biocontrol of vectors. A set of experimental tests was performed to determine the safe and effective dose of the extracts to be used for each test. The larvicidal bioassays performed on early fourth instar larvae of A. stephensi, A. aegypti and C.quinquefasciatus with ethyl acetate extract of Streptomyces sp. VITJS4 (Table I). The mortality rate

Table I

Larvicidal activity of ethyl acetate extract of Streptomyces sp. VITJS4 against the fourth-instar larvae of A. stephensi, A. aegypti and C. quinquefasciatus

\begin{tabular}{|c|c|c|c|c|c|c|}
\hline Species & $\begin{array}{c}\text { Concentration } \\
(\mathrm{ppm})\end{array}$ & $\begin{array}{c}\text { Percent }^{\mathrm{a}} \\
\text { mortality } \pm \mathrm{SD}\end{array}$ & $\begin{array}{l}\mathrm{LC}_{50}(\mathrm{ppm}) \\
\text { (LCL-UCL) }\end{array}$ & $\begin{array}{l}\mathrm{LC}_{90}(\mathrm{ppm}) \\
(\mathrm{LCL}-\mathrm{UCL})\end{array}$ & $r^{2}$ & $\chi^{2}(\mathrm{df}=4)$ \\
\hline A. stephensi & $\begin{array}{r}300 \\
240 \\
180 \\
120 \\
60\end{array}$ & $\begin{array}{c}100 \pm 0.000 \\
84 \pm 0.327 \\
62 \pm 0.894 \\
41 \pm 0.521 \\
29 \pm 0.438\end{array}$ & $132.86(126.61-139.48)$ & $396.14(275.02-412.31)$ & 0.992 & 9.678 \\
\hline A. aegypti & $\begin{array}{r}300 \\
240 \\
180 \\
120 \\
60\end{array}$ & $\begin{array}{l}98 \pm 0.521 \\
81 \pm 0.905 \\
59 \pm 0.848 \\
39 \pm 0.394 \\
28 \pm 0.486\end{array}$ & $112.78(106.67-119.04)$ & $336.42(319.47-360.26)$ & 0.987 & 7.376 \\
\hline C. quinquefasciatus & $\begin{array}{r}300 \\
240 \\
180 \\
120 \\
60\end{array}$ & $\begin{array}{c}100 \pm 0.000 \\
86 \pm 0.198 \\
63 \pm 0.637 \\
44 \pm 0.984 \\
30 \pm 1.091\end{array}$ & $156.53(150.28-163.43)$ & 468.37(419.19-486.09) & 0.993 & 8.800 \\
\hline
\end{tabular}

Control (distilled water) - nil mortality. $\mathrm{LC}_{50}$ and $\mathrm{LC}_{90}$ lethal concentration that kills 50 and $90 \%$ of the exposed larvae, UCL upper confidence limit, LCL lower confidence limit, $r^{2}$ regression coefficient. 
of $100,84,62,41$ and $29 \%$ were found against the fourth instar larvae of A. stephensi; 98, 81, 59, 39 and $28 \%$ against $A$. aegypti; and 100, 86, 63, 44 and 30\% against C.quinquefasciatus in the concentrations of $300,240,180,120$ and $60 \mathrm{ppm}$ respectively. The ethyl acetate extract of Streptomyces sp. VITJS4 showed highest mortality rate against the larvae of $A$. stephensi $\left(\mathrm{LC}_{50}=132.86\right.$ and $\left.\mathrm{LC}_{90}=396.14 ; \chi 2=9.678\right)$, A. aegypti
$\left(\mathrm{LC}_{50}=112.78\right.$ and $\left.\mathrm{LC}_{90}=336.42 ; \chi 2=7.376\right)$, C. quinquefasciatus with $\left(\mathrm{LC}_{50}=146.24\right.$ and $\mathrm{LC}_{90}=468.37$; $\chi^{2}=8.800$ ). The hexane, ethyl acetate, benzene, chloroform and methanol extracts of Streptomyces sp. VITJS4 showed significant repellence against A.stephensi, A. aegypti and C.quinquefasciatus (Tables II, III and IV). In this observation, the Streptomyces sp. VITJS4 extracts gave protection against mosquito bites without

Table II

Repellence of different extracts of Streptomyces sp. VITJS4 against the fourth-instar larvae of A. stephensi

\begin{tabular}{|c|c|c|c|c|c|c|c|c|c|}
\hline \multirow{2}{*}{ Solvents } & \multirow{2}{*}{$\begin{array}{l}\text { Concentration } \\
\left(\mathrm{mg} / \mathrm{cm}^{2}\right)\end{array}$} & \multicolumn{8}{|c|}{$\begin{array}{c}\% \text { of Repellency } \pm \text { SD } \\
\text { Time after application of repellent }(\mathrm{min})\end{array}$} \\
\hline & & 15 & 30 & 60 & 90 & 120 & 150 & 180 & 210 \\
\hline \multirow[t]{3}{*}{ Hexane } & 1.0 & $100 \pm 0.0$ & $100 \pm 0.0$ & $100 \pm 0.0$ & $100 \pm 0.0$ & $100 \pm 0.0$ & $74.5 \pm 0.4$ & $78.3 \pm 1.1$ & $79.2 \pm 0.5$ \\
\hline & 3.0 & $100 \pm 0.0$ & $100 \pm 0.0$ & $100 \pm 0.0$ & $100 \pm 0.0$ & $100 \pm 0.0$ & $81.1 \pm 1.8$ & $86.6 \pm 1.8$ & $81.7 \pm 1.9$ \\
\hline & 6.0 & $100 \pm 0.0$ & $100 \pm 0.0$ & $100 \pm 0.0$ & $100 \pm 0.0$ & $100 \pm 0.0$ & $87.9 \pm 1.4$ & $89.5 \pm 0.6$ & $82.9 \pm 0.3$ \\
\hline \multirow[t]{3}{*}{ Ethylacetate } & 1.0 & $100 \pm 0.0$ & $100 \pm 0.0$ & $100 \pm 0.0$ & $100 \pm 0.0$ & $100 \pm 0.0$ & $94.1 \pm 1.4$ & $90.4 \pm 0.5$ & $88.6 \pm 1.3$ \\
\hline & 3.0 & $100 \pm 0.0$ & $100 \pm 0.0$ & $100 \pm 0.0$ & $100 \pm 0.0$ & $100 \pm 0.0$ & $97.3 \pm 1.8$ & $93.2 \pm 0.4$ & $91.4 \pm 1.5$ \\
\hline & 6.0 & $100 \pm 0.0$ & $100 \pm 0.0$ & $100 \pm 0.0$ & $100 \pm 0.0$ & $100 \pm 0.0$ & $100 \pm 0.0$ & $99.7 \pm 1.0$ & $93.6 \pm 0.8$ \\
\hline \multirow[t]{3}{*}{ Benzene } & 1.0 & $100 \pm 0.0$ & $100 \pm 0.0$ & $100 \pm 0.0$ & $100 \pm 0.0$ & $100 \pm 0.0$ & $90 \pm 0.0$ & $82.2 \pm 1.1$ & $81.5 \pm 1.2$ \\
\hline & 3.0 & $100 \pm 0.0$ & $100 \pm 0.0$ & $100 \pm 0.0$ & $100 \pm 0.0$ & $100 \pm 0.0$ & $90.4 \pm 0.7$ & $87.1 \pm 0.4$ & $84.4 \pm 0.8$ \\
\hline & 6.0 & $100 \pm 0.0$ & $100 \pm 0.0$ & $100 \pm 0.0$ & $100 \pm 0.0$ & $100 \pm 0.0$ & $91.6 \pm 1.6$ & $83.0 \pm 1.6$ & $86.7 \pm 1.7$ \\
\hline \multirow[t]{3}{*}{ Chloroform } & 1.0 & $100 \pm 0.0$ & $100 \pm 0.0$ & $100 \pm 0.0$ & $100 \pm 0.0$ & $100 \pm 0.0$ & $89.5 \pm 1.0$ & $82.2 \pm 1.6$ & $80.9 \pm 0.4$ \\
\hline & 3.0 & $100 \pm 0.0$ & $100 \pm 0.0$ & $100 \pm 0.0$ & $100 \pm 0.0$ & $100 \pm 0.0$ & $90.7 \pm 0.6$ & $83.1 \pm 0.2$ & $83.3 \pm 0.9$ \\
\hline & 6.0 & $100 \pm 0.0$ & $100 \pm 0.0$ & $100 \pm 0.0$ & $100 \pm 0.0$ & $100 \pm 0.0$ & $92.2 \pm 1.2$ & $86.0 \pm 1.0$ & $85.0 \pm 0.8$ \\
\hline \multirow[t]{3}{*}{ Methanol } & 1.0 & $100 \pm 0.0$ & $100 \pm 0.0$ & $100 \pm 0.0$ & $100 \pm 0.0$ & $100 \pm 0.0$ & $90.1 \pm 0.0$ & $76.4 \pm 0.8$ & $79.9 \pm 0.2$ \\
\hline & 3.0 & $100 \pm 0.0$ & $100 \pm 0.0$ & $100 \pm 0.0$ & $100 \pm 0.0$ & $100 \pm 0.0$ & $92.1 \pm 0.0$ & $78.8 \pm 1.2$ & $81.3 \pm 1.3$ \\
\hline & 6.0 & $100 \pm 0.0$ & $100 \pm 0.0$ & $100 \pm 0.0$ & $100 \pm 0.0$ & $100 \pm 0.0$ & $96.3 \pm 0.5$ & $78.0 \pm 1.6$ & $83.0 \pm 0.4$ \\
\hline
\end{tabular}

Table III

Repellence of different extracts of Streptomyces sp. VITJS4 against the fourth-instar larvae of A. aegypti

\begin{tabular}{|c|c|c|c|c|c|c|c|c|c|}
\hline \multirow{2}{*}{ Solvents } & \multirow{2}{*}{$\begin{array}{c}\text { Concentration } \\
\left(\mathrm{mg} / \mathrm{cm}^{2}\right)\end{array}$} & \multicolumn{8}{|c|}{$\begin{array}{c}\% \text { of Repellency } \pm \text { SD } \\
\text { Time after application of repellent }(\mathrm{min})\end{array}$} \\
\hline & & 15 & 30 & 60 & 90 & 120 & 150 & 180 & 210 \\
\hline \multirow[t]{3}{*}{ Hexane } & 1.0 & $100 \pm 0.0$ & $100 \pm 0.0$ & $100 \pm 0.0$ & $100 \pm 0.0$ & $100 \pm 0.0$ & $97.2 \pm 1.0$ & $91.3 \pm 0.6$ & $76.2 \pm 0.7$ \\
\hline & 3.0 & $100 \pm 0.0$ & $100 \pm 0.0$ & $100 \pm 0.0$ & $100 \pm 0.0$ & $100 \pm 0.0$ & $95.1 \pm 1.2$ & $87.6 \pm 0.4$ & $76.7 \pm 1.2$ \\
\hline & 6.0 & $100 \pm 0.0$ & $100 \pm 0.0$ & $100 \pm 0.0$ & $100 \pm 0.0$ & $100 \pm 0.0$ & $91.4 \pm 0.6$ & $82.5 \pm 0.6$ & $76.9 \pm 0.4$ \\
\hline \multirow[t]{3}{*}{ Ethyl acetate } & 1.0 & $100 \pm 0.0$ & $100 \pm 0.0$ & $100 \pm 0.0$ & $100 \pm 0.0$ & $100 \pm 0.0$ & $97.1 \pm 1.4$ & $90.2 \pm 1.1$ & $80.5 \pm 1.2$ \\
\hline & 3.0 & $100 \pm 0.0$ & $100 \pm 0.0$ & $100 \pm 0.0$ & $100 \pm 0.0$ & $100 \pm 0.0$ & $99.3 \pm 1.8$ & $92.1 \pm 0.4$ & $84.4 \pm 0.8$ \\
\hline & 6.0 & $100 \pm 0.0$ & $100 \pm 0.0$ & $100 \pm 0.0$ & $100 \pm 0.0$ & $100 \pm 0.0$ & $100 \pm 0.0$ & $99.0 \pm 1.6$ & $88.7 \pm 1.7$ \\
\hline \multirow[t]{3}{*}{ Benzene } & 1.0 & $100 \pm 0.0$ & $100 \pm 0.0$ & $100 \pm 0.0$ & $100 \pm 0.0$ & $100 \pm 0.0$ & $96.2 \pm 0.4$ & $80.1 \pm 1.1$ & $72.3 \pm 0.7$ \\
\hline & 3.0 & $100 \pm 0.0$ & $100 \pm 0.0$ & $100 \pm 0.0$ & $100 \pm 0.0$ & $100 \pm 0.0$ & $92.1 \pm 1.2$ & $86.1 \pm 0.4$ & $74.5 \pm 0.8$ \\
\hline & 6.0 & $100 \pm 0.0$ & $100 \pm 0.0$ & $100 \pm 0.0$ & $100 \pm 0.0$ & $100 \pm 0.0$ & $89.7 \pm 0.4$ & $89.0 \pm 1.6$ & $79 \pm 1.0$ \\
\hline \multirow[t]{3}{*}{ Chloroform } & 1.0 & $100 \pm 0.0$ & $100 \pm 0.0$ & $100 \pm 0.0$ & $100 \pm 0.0$ & $100 \pm 0.0$ & $95.2 \pm 0.6$ & $80.2 \pm 1.0$ & $76.3 \pm 0.3$ \\
\hline & 3.0 & $100 \pm 0.0$ & $100 \pm 0.0$ & $100 \pm 0.0$ & $100 \pm 0.0$ & $100 \pm 0.0$ & $93.5 \pm 1.0$ & $80.5 \pm 0.2$ & $78.9 \pm 0.7$ \\
\hline & 6.0 & $100 \pm 0.0$ & $100 \pm 0.0$ & $100 \pm 0.0$ & $100 \pm 0.0$ & $100 \pm 0.0$ & $90.1 \pm 1.2$ & $83.7 \pm 0.4$ & $82.0 \pm 1.2$ \\
\hline \multirow[t]{3}{*}{ Methanol } & 1.0 & $100 \pm 0.0$ & $100 \pm 0.0$ & $100 \pm 0.0$ & $100 \pm 0.0$ & $100 \pm 0.0$ & $90 \pm 0.0$ & $86.1 \pm 0.4$ & $79.3 \pm 0.7$ \\
\hline & 3.0 & $100 \pm 0.0$ & $100 \pm 0.0$ & $100 \pm 0.0$ & $100 \pm 0.0$ & $100 \pm 0.0$ & $90.1 \pm 0.5$ & $92.3 \pm 0.6$ & $81.6 \pm 1.2$ \\
\hline & 6.0 & $100 \pm 0.0$ & $100 \pm 0.0$ & $100 \pm 0.0$ & $100 \pm 0.0$ & $100 \pm 0.0$ & $94.8 \pm 1.0$ & $93.0 \pm 0.2$ & $83.5 \pm 0.2$ \\
\hline
\end{tabular}


Table IV

Repellence of different extracts of Streptomyces sp. VITJS4 against the fourth-instar larvae of C. quinquefasciatus

\begin{tabular}{|c|c|c|c|c|c|c|c|c|c|}
\hline \multirow{2}{*}{ Solvents } & \multirow{2}{*}{$\begin{array}{l}\text { Concentration } \\
\left(\mathrm{mg} / \mathrm{cm}^{2}\right)\end{array}$} & \multicolumn{8}{|c|}{$\begin{array}{c}\% \text { of Repellency } \pm \text { SD } \\
\text { Time after application of repellent (min) }\end{array}$} \\
\hline & & 15 & 30 & 60 & 90 & 120 & 150 & 180 & 210 \\
\hline \multirow[t]{3}{*}{ Hexane } & 1.0 & $100 \pm 0.0$ & $100 \pm 0.0$ & $100 \pm 0.0$ & $100 \pm 0.0$ & $100 \pm 0.0$ & $96.2 \pm 0.6$ & $80.2 \pm 1.0$ & $76.3 \pm 0.3$ \\
\hline & 3.0 & $100 \pm 0.0$ & $100 \pm 0.0$ & $100 \pm 0.0$ & $100 \pm 0.0$ & $100 \pm 0.0$ & $93.5 \pm 1.0$ & $83.5 \pm 0.2$ & $76.9 \pm 0.7$ \\
\hline & 6.0 & $100 \pm 0.0$ & $100 \pm 0.0$ & $100 \pm 0.0$ & $100 \pm 0.0$ & $100 \pm 0.0$ & $91.1 \pm 1.2$ & $83.7 \pm 0.4$ & $82.0 \pm 1.2$ \\
\hline \multirow[t]{3}{*}{ Ethyl acetate } & 1.0 & $100 \pm 0.0$ & $100 \pm 0.0$ & $100 \pm 0.0$ & $100 \pm 0.0$ & $100 \pm 0.0$ & $100 \pm 0.0$ & $92.4 \pm 0.8$ & $90.2 \pm 0.7$ \\
\hline & 3.0 & $100 \pm 0.0$ & $100 \pm 0.0$ & $100 \pm 0.0$ & $100 \pm 0.0$ & $100 \pm 0.0$ & $100 \pm 0.6$ & $96.7 \pm 0.6$ & $91.6 \pm 1.2$ \\
\hline & 6.0 & $100 \pm 0.0$ & $100 \pm 0.0$ & $100 \pm 0.0$ & $100 \pm 0.0$ & $100 \pm 0.0$ & $100 \pm 1.2$ & $99.0 \pm 1.2$ & $96.7 \pm 0.4$ \\
\hline \multirow[t]{3}{*}{ Benzene } & 1.0 & $100 \pm 0.0$ & $100 \pm 0.0$ & $100 \pm 0.0$ & $100 \pm 0.0$ & $100 \pm 0.0$ & $98.2 \pm 1.0$ & $81.3 \pm 0.6$ & $71.2 \pm 0.7$ \\
\hline & 3.0 & $100 \pm 0.0$ & $100 \pm 0.0$ & $100 \pm 0.0$ & $100 \pm 0.0$ & $100 \pm 0.0$ & $95.1 \pm 1.2$ & $87.6 \pm 0.4$ & $74.7 \pm 1.8$ \\
\hline & 6.0 & $100 \pm 0.0$ & $100 \pm 0.0$ & $100 \pm 0.0$ & $100 \pm 0.0$ & $100 \pm 0.0$ & $91.4 \pm 0.6$ & $90.5 \pm 0.6$ & $76.9 \pm 0.4$ \\
\hline \multirow[t]{3}{*}{ Chloroform } & 1.0 & $100 \pm 0.0$ & $100 \pm 0.0$ & $100 \pm 0.0$ & $100 \pm 0.0$ & $100 \pm 0.0$ & $98.3 \pm 0.4$ & $82.2 \pm 1.6$ & $76.3 \pm 0.4$ \\
\hline & 3.0 & $100 \pm 0.0$ & $100 \pm 0.0$ & $100 \pm 0.0$ & $100 \pm 0.0$ & $100 \pm 0.0$ & $94.7 \pm 0.6$ & $86.1 \pm 0.2$ & $80.9 \pm 0.3$ \\
\hline & 6.0 & $100 \pm 0.0$ & $100 \pm 0.0$ & $100 \pm 0.0$ & $100 \pm 0.0$ & $100 \pm 0.0$ & $90.6 \pm 1.0$ & $92.3 \pm 0.6$ & $86.8 \pm 0.8$ \\
\hline \multirow[t]{3}{*}{ Methanol } & 1.0 & $100 \pm 0.0$ & $100 \pm 0.0$ & $100 \pm 0.0$ & $100 \pm 0.0$ & $100 \pm 0.0$ & $97.2 \pm 0.6$ & $80.2 \pm 1.2$ & $72.3 \pm 0.6$ \\
\hline & 3.0 & $100 \pm 0.0$ & $100 \pm 0.0$ & $100 \pm 0.0$ & $100 \pm 0.0$ & $100 \pm 0.0$ & $94.2 \pm 0.3$ & $86.5 \pm 0.6$ & $75.4 \pm 0.4$ \\
\hline & 6.0 & $100 \pm 0.0$ & $100 \pm 0.0$ & $100 \pm 0.0$ & $100 \pm 0.0$ & $100 \pm 0.0$ & $90.9 \pm 1.7$ & $90.7 \pm 0.4$ & $82.1 \pm 1.2$ \\
\hline
\end{tabular}

any allergic reaction to the test person and also, the repellent activity was dependent on the strength of the crude extract. The highest repellence at 150, 180 and 210 min. was observed with Streptomyces sp. VITJS4 ethyl acetate crude extract at the dosage of $6 \mathrm{mg} / \mathrm{cm}^{2}$ against A.stephensi, A.aegypti and C.quinquefasciatus. The partial characterization of the crude extracts showed the presence of functional groups which was revealed by IR spectra. The FTIR spectral analyses of ethyl acetate crude extracts showed certain common absorption bands at 3359 and $3251 \mathrm{~cm}^{-1}$ which are characteristics of the hydroxyl group $(\mathrm{O}-\mathrm{H})$. The vibrational peaks at $2116 \mathrm{~cm}^{-1}$ and $1630 \mathrm{~cm}^{-1}$ were alkynes $(\mathrm{C} \equiv \mathrm{C})$ and alkene $(\mathrm{C}=\mathrm{C})$ functional groups, respectively (Fig. 1). The research work is ongoing with the goal of isolating the identified compounds and characterizing the structure of the compounds in the most active crude extract.

\section{Discussion}

Vector borne diseases are the major treats to human which has led to tremendous economic impacts such as malaria, filariasis, dengue, yellow fever and encephalitis are continuing to be major health problems for the people (Das and Ansari, 2003). The exposure to pesticides among humans has been linked to immune dysfunction, various forms of cancer and birth defects (Nigam and Venkatakrishna Bhatt, 2001). As to control the injudicious use of pesticides, it is therefore necessary to identify a safe, eco-friendly alternate source of larvi- cide in order to reduce mosquito menace (Nascimento et al., 2000). Natural products contribute as the source of novel bioactive metabolites. The discovery of new active metabolites must be followed by adequate biological testing (Jemimah Naine et al., 2012). A few numbers of larvicidal and repellent drugs have been discovered from natural products in the past and new ones are being developed. Recently turning back to nature, the marine environment represents an inexhaustible resource of new compounds with unique structures from wide range of microorganisms. The larvicidal activity of extracellular metabolites of keratinophilic fungus Trichophyton mentagrophytes was found effective against $3^{\text {rd }}$ instar larvae of $A$. aegypti $\mathrm{LC}_{50}$ and $\mathrm{LC}_{90}$ being $110 \pm 11.5$ and $200 \pm 20.7$ respectively after 2 days (Murugesan et al., 2009). A novel polyketide metabolite from marine Streptomyces sp. AP-123 was found to exhibit high larvicidal activities against Helicoverpa armigera (63.11\%) and Spodoptera litura (58.22\%) and the $\mathrm{LC}_{50}$ values were $645.25 \mathrm{ppm}$ and $806.54 \mathrm{ppm}$ respectively (Arasu et al., 2013). The spinosad from the actinomycete, Saccharopolyspora. spinosa, showed $\mathrm{LC}_{50}$ and $\mathrm{LC}_{90}$ values of first, second, third and fourth-instar larvae at $0.001,0.031,0.034,0.036$ and $0.0113,0.102$, 0.111, 0.113 ppm (Das and Ansari., 2003). Twenty three isolates of actinomycetes showed positive larvicidal activity against $A$. aegypti. Among the 23 isolates, four isolates were Streptomyces (A14, A21, A49 and A63) and found to be more active against the larvae of $A$. aegypti with $\mathrm{LC}_{50}$ value ranging between 15.83 and $68.06 \mu \mathrm{g} / \mathrm{ml}$. Three new alpha-class milbemycins (named milbemycins alpha-28, alpha-29 and alpha-30) isolated from 


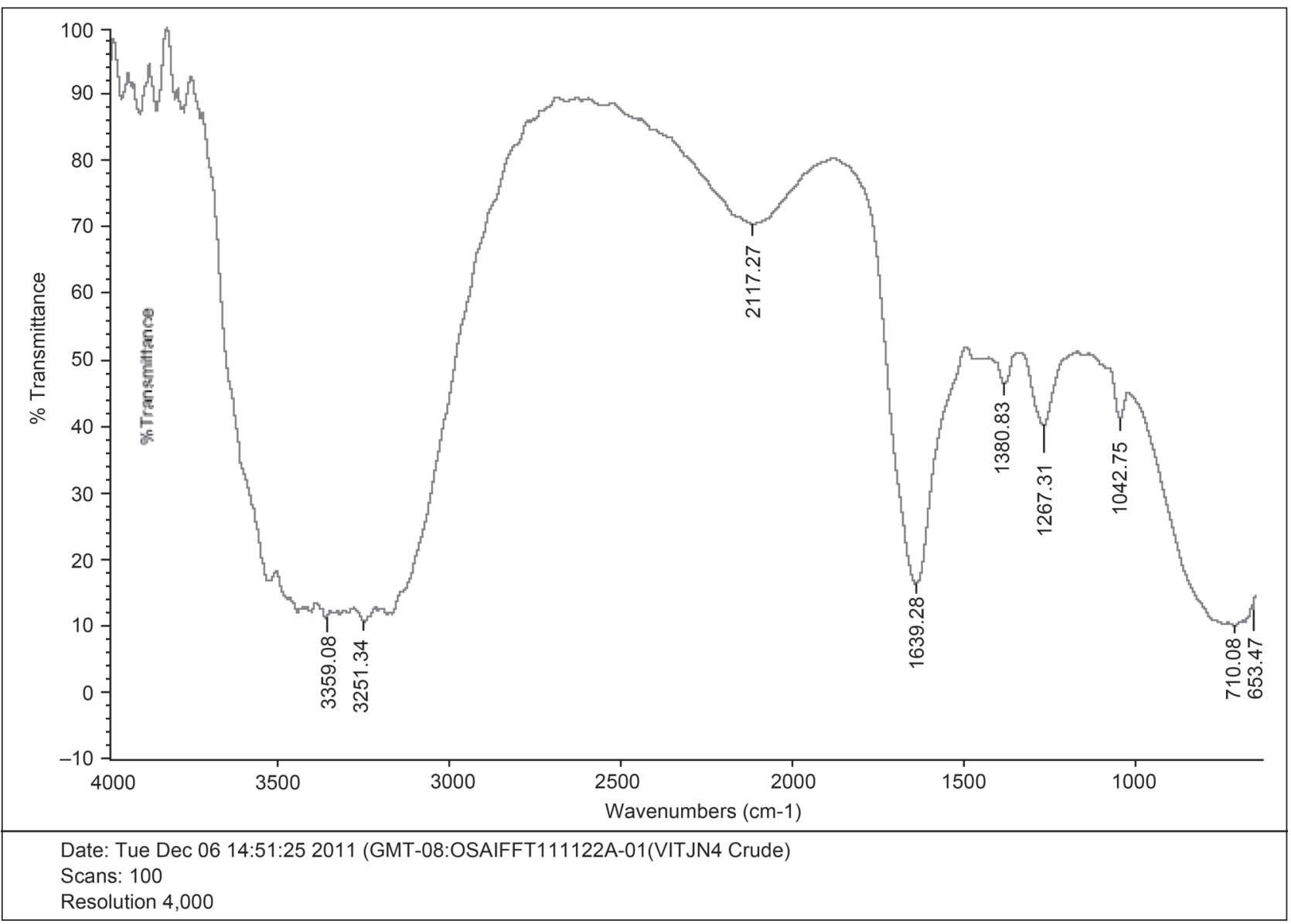

Fig. 1. FTIR analysis of Streptomyces sp. VITJS4 ethyl acetate crude extract.

Streptomyces bingchenggensis have been shown to possess potent acaricidal and nematocidal activity (Xiang et al., 2007). Recent studies have indicated that spinosad, a mixture of two tetracyclic macrolide compounds produced during the fermentation of a soil actinomycete, may be suitable for controlling a number of medically important mosquito species, including the dengue vector, A. aegypti (Antonio et al., 2009). The relevant studies of a novel isolated compound 5-(2,4-dimethylbenzyl) pyrrolidin-2-one from marine Streptomyces VITSVK5 sp. was found to have complete larvicidal activity at 1000 ppm against Rhipicephalus (Boophilus) microplus, A. stephensi and Culex tritaeniorhynchus and the $\mathrm{LC}_{50}$ values were $210.39 \mathrm{ppm}, 169.38 \mathrm{ppm}$, 198.75 ppm, respectively (Saurav et al., 2013). In the present study, isolate Streptomyces sp. VITJS4 ethyl acetate crude extract exhibited $\mathrm{LC}_{50}$ and $\mathrm{LC}_{90}$ value of 132.86 and 396.14 against $A$. stephensi larvae, 112.78 and 336.42 against $A$. aegypti larvae, 156.53 and 468.37 against $C$. quinquefasciatus larvae which is comparable with supporting report showing 35 isolates with larvicidal activity against C.quinquefasciatus, A. stephensi and A. aegypti (Vijayan et al., 1991). Interestingly, the data on repellent assay of Streptomyces sp. VITJS4 ethylacetate crude extracts showed complete protection for
$210 \mathrm{~min}$ at the dosage of $6 \mathrm{mg} / \mathrm{cm}^{2}$ against mosquito bites of A. stephensi, A. aegypti and C. quinquefasciatus. The larvicidal compound (2S,5R,6R)-2-hydroxy-3,5,6trimethyloctan-4-one from Streptomyces sp. against blood-sucking parasites was found to have complete larvicidal activity at $250 \mathrm{ppm}$ against $R$. microplus, A. subpictus and C. quinquefasciatus and the $\mathrm{LC}_{50}$ values were $94.49 \mathrm{ppm}, 69.65 \mathrm{ppm}, 82.82 \mathrm{ppm}$, respectively (Deepika et al., 2012). The crude extracts of LK-3 and LK-1 with the highest concentrations of $1,000 \mathrm{ppm}$ provided over 120 and 90 min protection against Culex gelidus bites (Karthik et al., 2011). The results of the present study support previous observation that marine sediments are the sources of metabolically active Streptomyces (Moran et al., 1995). The crude extracts are attributed with complex mixtures of several active compounds and may facilitate the future application of biotechnological procedures for cost-effective production. The significant properties of bioactive potential perhaps serve as a promising source and could act as a new mode of controlling mosquitoes.

\section{Acknowledgements}

The authors wish to thank the management of VIT University for providing the facilities to carry out this study. 


\section{Literature}

Ahmed S., M. Graivge, J.W. Hylin, W.C. Mitchell and J.A. Listinger. 1984. Some promising plant species for use as pest control agents under traditional farming system. In: Natural Pesticides from the neem tree (Azadirachtaindica A. Juss) and Other Tropical Plants. 565-80.

Amer A. and H. Mehlhorn. 2006. Larvicidal effects of various essential oils against Aedes, Anopheles and Culex larvae (DipteraCulicidae). Parasitol Res. 99: 466-472.

Antonio G.E., D. Sánchez, T. Williams and C.F. Marina. 2009. Paradoxical effects of sub lethal exposure to the naturally derived insecticide spinosad in the dengue vector mosquito, Aedes aegypti. Pest Manag Sci. 65(3): 323-326

Arasu M.V., A.N. Abdullah, S. Valsalam, D. Veeramuthu, M. Chinnasamy and K. Sun-Ju. 2013. Antifeedant, larvicidal and growth inhibitory bioactivities of novel polyketide metabolite isolated from Streptomyces sp. AP-123 against Helicoverpa armigera and Spodoptera litura. BMC Microbiol. 13: 105.

Berdy J. 2005. Bioactive microbial metabolites: a personal view. J. Antibiot. 58(1): 1-26.

Bibb M.J. 2005. Regulation of secondary metabolism in Streptomycetes. Curr Opin Microbiol.8: 208-215.

Blunt J.W. 2006. Prinsep MR. Marine natural products. Nat. Prod. Rep. 23: 26-78.

Buchanan R.E. and N.E. Gibbons. 1974. Bergey's manual of determinative bacteriology, 8th edn. The Williams and Wilkins Co., Baltimore, $\mathrm{p} 1146$.

Carlos J.P.C., C. Araújo, C.B. Thaissa, E.S. Pires, L.V.S. Eschb, A.B.P. Viviani and C.F.G. Cavados. 2011. Investigation of biota associated and natural infection by sporulated bacteria in Culicidae larvae from Sao Paulo state, Brazil. J. Invert. Pathol. 107: 11-15.

Chand S.K., N.K. Tripathy and C.C. Das. 1988. Some environmental factors affecting Culex quinquefasciatus population in a coastal town, Gopalpur on sea. Orissa. Geobios. 15: 53-56.

Das M.K. and M.A. Ansari. 2003. Evaluation of repellent action of Cymbopogan martinii martini. Stapf var sofia oil against Anopheles sundaicus in tribal villages of Car Nicobar Island, India. J. Vector Borne Dis. 40(3-4): 100-104.

Deepika T.L., K. Kannabiran, V.G. Khanna, G. Rajakumar, C. Jayaseelan, T. Santhoshkumar and A.A. Rahuman. 2012. Isolation and characterisation of acaricidal and larvicidal novel compound (2S,5R,6R)-2-hydroxy-3,5,6-trimethyloctan-4-one from Streptomyces sp. against blood-sucking parasites Parasitology res. 111(3): 1151-1163

Deepika T. L. and K. Kannabiran. 2009. A morphological, biochemical and biological studies of halophilic Streptomyces sp. isolated from saltpan environment. Am. J. Infec. Dis. 5(3): 207-213.

Eberhardt T. L., X. Li, T.F. Shupe and C.Y. Hse. 2007. Chinese tallow tree (Sapium Sebiferum) utilization: Characterization of extractives and cell-wall chemistry Wood Fiber Sci. 39: 319-324.

Fradin M. S. and J.F. Day. 2002. Comparative efficacy of insect repellents against mosquito bite. New. Engl. J. Med. 347: 13-18.

Hazra K.M., R.N. Roy, S.K. Sen and S. Laska. 2007. Isolation of antibacterial pentahydroxy flavones from the seeds of Mimusops elengi Linn. Afr. J. Biotechnol. 6 (12): 1446-1449.

Ikemoto T., T. Katayama, A. Shiraishi and T. Haneishi. 1983. Aculeximycin, a new antibiotic from Streptosporangium albidum. II. Isolation, physicochemical and biological properties. J. Antibiot. Tokyo. 36(9): 1097-1100

Jang Y. S., M.K. Kim, Y.J. Ahn and H.S. Lee. 2002. Larvicidal activity of brazilian plants against Aedes aegypti and Culex pipienspallens (Diptera:Culicidae). Agric. Chem. Biotechnol. 45(3): 131-134. Jemimah Naine S., N. Nasimunislam, B. Vaishnavi, V. Mohanasrinivasan and C. Subathra Devi. 2012. Isolation of soil actinomy- cetes inhabiting amirithi forest for the potential source of bioactive compounds. Asian. J. Pharm. Clin. Res. 5(4): 189-192.

Jemimah Naine, S., V. Mohana Srinivasan and C. Subathra Devi. 2011. Novel anticancer compounds from marine actinomycetes. J. Pharm. Res. 4 (4): 1285-1287.

Jensen P.R., T.J. Mincer, P.G. Williams and W. Fenical. 2005 Marine actinomycete diversity and natural product discovery. Anton. Leeuw. Int. J. 87: 43-48

Kamaraj C., A. Bagavan, A. Rahuman, A.A. Zahir, G. Elango and G. Pandiyan. 2009. Larvicidal potential of medicinal plant extracts against Anopheles subpictus Grassi and Culex tritaeniorhynchus Giles (Diptera: Culicidae). Parasitol. Res. 104: 1163-1171.

Karthik L., K. Gaurav, V.B. Rao, G. Rajakumar and A.A. Rahuman, 2011. Larvicidal, repellent, and ovicidal activity of marine actinobacteria extracts against Culex tritaeniorhynchus and Culex gelidus. Parasitol. Res. 108: 1447-1455.

Klempner M. S., T.R. Unnasch and L.T. Hu. 2007. Taking a bite out of vector-transmitted infectious diseases. N. Engl. J. Med. 356: 2567-2569.

Kondrachine A.V. 1992. Malaria in WHO Southeast Asia region. Ind. J. malariol. 29: 129-160.

Kundsen A.B. and R. Slooff. 1992. Vector-borne disease problems in rapid urbanization: new approaches to vector control. Bull. World Health Org. 70: 1-6.

Lechevalier M.P. and H. Lechevalier. 1970. Chemical composition as a criterion in the classification of aerobic actinomycetes. Int. J. Syst. Bacteriol. 20: 435-443

Macleod R.A. 1965. The question of the existence of specific marine bacteria. Bacteriol rev. 29: 9-23.

Maheswaran R., S. Sathis and S. Ignacimuthu. 2008. Larvicidal activity of Leucus aspera (Wild.) against the larvae of Culex quinquefasciatus and Aedes aegypti L. Int. Journal. of Int. Biol. 2(3): 214-217 Mann J. 2001. Natural products as immunosuppressive agents. Nat. Prod. Rep. 18: 417-430

Moran M.A., L.T. Rutherford and R.E. Hodson. 1995. Evidence for indigenous Streptomyces populations in a marine environment determined with a $16 \mathrm{~S}$ r-RNA probe. Appl. Environ. Microbiol. 61 : 3695-3700.

Murugesan A.G., C. Satheshprabu and C. Selvakumar. 2009. Bio larvicidal activity of Extracellular metabolites of the keratinophilic fungus Trichophyton mentagrophytes against larvae of A.aegypti - a Major Vector for Chikungunya and Dengue. Folia Microbiol. 54 (3): 213-216.

Nascimento G.G.F., J. Locatelli, P.C. Freitas and G. Silva. 2000. Antibacterial activity of plant extracts and phytochemicals on antibiotic resistant bacteria. Braz. J. of Microbiol. 31: 247-256.

Nigam S.K. and H. Venkatakrishna-Bhatt. 2001. Occupational cancer: Introduction and intervention. Ind. J. Occup. Hlth. 44: 79-88. Nonomura H. 1974. Key for classification and identification of 458 species of the Streptomycetes included in ISP. J. Ferment. Technol. 52(2): 78-92.

Patil C.D., S.V. Patil, B.K. Salunke and R.B. Salunkhe. 2011. Bio efficacy of Plumbago zeylanica (Plumbaginaceae) and Cestrum nocturnum (Solanaceae) plant extracts against Aedes aegypti (Diptera: Culicidae) and non-target fish Poeciliareticulata. Parasitol Res. 108(5): 1253-1263.

Prauser H. 1964. Aptness and application of color for exact description of color of Streptomyces. Z. Allgemeine. Microbiol. 4: 95-98

Rahuman A.A., A. Bagavan, C. Kamaraj, E. Saravanan, A.A. Zahir and G. Elango. 2009. Efficacy of larvicidal botanical extracts against Culex quinquefasciatus Say (Diptera: Culicidae). Parasitol Res. 104(6): 1365-1372.

Rawani A., A. Ghosh and G. Chandra. 2010. Mosquito larvicidal activities of Solanum nigrum L. leaf extract against Culex quinquefasciatus Say. Parasitol. Res. 107(5): 1235-1240. 
Remya M. and R. Vijayakumar. 2007. Isolation and characterization of marine antagonistic actinomycetes from west coast of India. Med. Biol. 5: 13-19.

Sanglier J.J., E.M.H. Wellington, V. Behal, H.P. Feidler, R.E. Ghorbel, C. Finance, M. Hacene, A. Kamoun, C. Kelly, D.K. Mercer, S. Prinzis and C. Tringo. 1993. Novel bioactive compounds from actinomycetes. Res. Microbiol.144: 661-663.

Santos S.R., M.A. Melo, A.V. Cardoso, R.L. Santos, D.P. de Sousa and S.C. Cavalcanti. 2011. Structure-activity relationships of larvicidal monoterpenes and derivatives against Aedes aegypti Linn. Chemosphere 84(1): 150-153.

Saurav K., G. Rajakumar, K. Kannabiran, A.A. Rahuman, K. Velayutham, G. Elango, C. Kamaraj and A.A. Zahir. 2013. Larvicidal activity of isolated compound 5-(2,4-dimethylbenzyl) pyrrolidin-2-one from marine Streptomyces VITSVK5 sp. against
Rhipicephalus (Boophilus) microplus, Anopheles stephensi, Culex tritaeniorhynchus. Parasitol Res. 112(1): 215-226.

Shirling E.B. and D. Gottlieb. 1966. Methods for characterization of Streptomyces species. Int J Syst Bacteriol. 16: 313-340.

Strohl W.R. 2004. Antimicrobials. In: Bull AT (ed) Microbial diversity and bio prospecting. ASM, Washington, pp 288-313.

Venkatachalam M.R. and A. Jebanesan. 2001. Repellent activity of Ferronia elephantum Corr. (Rutaceae) leaf extract against Aedes aegypti. Bioresour Tech. 76(3): 287-288.

Vijayan V. and K. Balaraman. 1991. Metabolites of fungi and actinomycetes active against mosquito larvae. Indian J. Med. Res. 93: 115-117. Xiang W.S., J.D. Wang, X.J. Wang, J. Zhang and Z. Wang. 2007. Further new milbemycin antibiotics from Streptomyces bingchenggensis. Fermentation, isolation, structural elucidation and biological activities. J. Antibiot. 60(10): 608-613. 